\title{
MeCANismos de GovernanÇA Corporativa NO BRASIL: EVIDÊNCIAS do Controle pelo Mercado de Capitais
}

\author{
Prof. Pablo Rogers \\ Mestre em Administração - FAGEN/UFU, \\ Professor de Finanças da FAGEN/UFU \\ msc_pablo@yahoo.com.br \\ wrwe.pablo.prof.ufu.br
}

\author{
Profa ${ }^{\text {a }}$ Kárem Cristina de Sousa Ribeiro \\ Doutora e Pós-Doutora em Administração FEA/USP \\ Professora de Finanças da FAGEN/UFU \\ kribeiro@ufu.br
}

\section{RESUMO}

Esse trabalho tem por objetivo fazer uma discussão dos mecanismos de governança corporativa no Brasil, especialmente o controle externo pelo mercado de capitais. Em termos específicos faz-se uma revisão bibliográfica de pesquisas que avaliaram a performance: a) do Índice de Governança Corporativa (IGC), indexado a partir de Junho de 2001; e b) de empresas que possuem American Depositary Receipts (ADR's). Tomados os trabalhos que avaliaram a performance do IGC no seu conjunto evidencia-se que esse índice não apresentou melhor performance em relação aos outros da Bovespa. Entretanto, os estudos que relacionam a performance de empresas emitentes de ADR's com as práticas de governança corporativa evidenciaram certa convergência nas conclusões, mostrando, no geral, que as empresas que optaram pelo lançamento de ADR's apresentaram melhor performance após a emissão do recibo.

Palavras-Chave: Governança Corporativa, Mercado de Capitais, Índice de Governança Corporativa, American Depositary Receipts.

\section{ABSTRACT}

The objective of this paper is to discuss the mechanisms of corporative governance in Brazil, especially the external control through the stock market. In specific terms, a bibliographical revision was made, evaluating the performance of a) The Corporate Governance Index (IGC), indexed from June of 2001; b) companies that possess the American Depositary Receipts (ADR's). Considering the procedures that evaluated the IGC performance on its set, in general, a non conclusion of the best performance of this index in relation to others of the São Paulo's Stock Exchange was evidenced. However, studies that relate performance of $A D R$ 's issuing companies to the practices of corporate governance evidenced a convergence in conclusions, showing that, in general, companies that made an option for the ADR's presented a better performance after its issuance.

KEY WORDs: Corporate Governance, Stock Market, Corporate Governance Index, American Depositary Receipts. 


\section{INTRODUÇÃO}

De acordo com Vieira e Corrêa (2002), o mercado de capitais brasileiro sempre esteve à margem do arranjo financeiro nacional. Entretanto, nas décadas de 80 e 90, surgiram inovações financeiras que possibilitaram a alavancagem de recursos via lançamentos de títulos de dívida direta (ADR's, por exemplo), que necessariamente tornou o mercado de capitais nacional mais dinâmico. Adicionalmente, a abertura econômica e financeira propagada na década de 90 aumentou a entrada de recursos nesse mercado, incentivando o seu desenvolvimento.

Apesar do relativo desenvolvimento na década de 90, o mercado de capitais brasileiro ainda é pouco desenvolvido, apresentando como características principais: a) baixa capitalização bursátil; b) inexpressivo volume transacionado; c) poucas emissões primárias; d) reduzido número de companhias abertas; e) alta concentração das transações em poucas ações; e f) baixa liquidez.

Segundo Carvalho (2002), a base da atrofia do mercado de capitais nacional está no baixo nível de proteção do qual gozam acionistas minoritários e credores no Brasil, sendo esses os principais conflitos de agência encontrados no país. A proteção legal aos acionistas minoritários é justificada em várias pesquisas internacionais. La Porta et. al. (1998 e 1999) ressaltam que quando grandes acionistas controlam uma empresa, suas políticas podem resultar em expropriação dos acionistas minoritários, reduzindo o valor da mesma. Os autores sugerem que a desigualdade na proteção legal dos investidores e a garantia de sua aplicação entre os diversos sistemas de governança corporativa no mundo causam diferenças na estrutura de propriedade, política de dividendos, disponibilidade de recursos externos e valorização dos papéis das empresas no mercado de capitais. La Porta et al. (1998) afirmam, em estudo empreendido com 49 países - incluindo o Brasil, que a concentração de propriedade acionária é negativamente relacionada à proteção dos direitos dos acionistas e países com melhores proteções legais tendem a apresentar uma maior dispersão da propriedade e valor das empresas.

O conflito de agência existente entre acionistas minoritários versus majoritários, assim como os conflitos existentes entre credores e acionistas, são tratados na temática de governança corporativa. No que tange a esse aspecto, enuncia-se, de acordo com Andrade e Rossetti (2004, p.25), que governança corporativa é "um conjunto de valores, princípios, propósitos, papéis, regras e processos que rege o sistema de poder e os mecanismos de gestão das empresas", abrangendo como um dos tópicos a maximização da riqueza dos acionistas, minimizando oportunismos conflitantes com este fim, inclusive com a minimização do conflito de agência existente entre acionistas minoritários e majoritários. Diante dessa perspectiva, a chave é criar mecanismos de controle ex-ante que inibam os conflitos de agência e minimizem os custos ex-post.

No Brasil, uns dos principais e mais atuantes mecanismos de controle externo instituídos, foram o Novo Mercado e os Níveis Diferenciados da Bovespa. Nessas instituições, as empresas, por meio de um contrato privado voluntário, aderem a regras que exigem a adoção de práticas de governança corporativas superiores, funcionando o Novo Mercado e os Níveis Diferenciados como um selo de qualidade.

Outro mecanismo externo de controle importante, que também funciona como selo de qualidade de boas práticas de governança corporativa, é a emissão de American Depositary Receipts (ADR's). Admite-se que empresas possuidoras de ADR's apresentam práticas de governança corporativa superiores em decorrência das exigências da Securities and Exchange Commission (SEC - órgão regulador do mercado de capitais americano) para o lançamento de títulos de empresas brasileiras no mercado norte-americano.

Este trabalho tem por objetivo discutir, por meio de uma revisão bibliográfica de recentes pesquisas empíricas, especialmente esses dois mecanismos de controle externo de governança corporativa no Brasil: 1) o Novo Mercado e os Níveis Diferenciados da Bovespa; 2) e empresas que possuem ADR's.

$\mathrm{Na}$ próxima seção apresentam-se os mecanismos de governança corporativa e seus desdobramentos no Brasil, para posteriormente discutir os mecanismos externos de controle de governança corporativa pelo mercado de capitais. Na seção três, apresentam-se o Novo Mercado e os Níveis Diferenciados da Bovespa, e na seção quatro são revisadas as evidências empíricas que avaliaram a performance de empresas pertencentes ao Novo Mercado e aos Níveis Diferenciados vis-a-vis o mercado tradicional. A performance será analisada em quatro principais aspectos: liquidez, volatilidade (risco), retorno e valor, e custo de captação (custo de capital). Aproveitando esses quatro aspectos, também na seção cinco apresentam-se as evidências empíricas que avaliaram a performance de empresas emitentes de ADR's. $\mathrm{Na}$ seção seis, a partir da análise da revisão bibliográfica procedida, faz-se a conclusão do estudo e sugestões para pesquisas posteriores.

\section{MECANISMOS DE GOVERNANÇA CORPORATIVA NO BRASIL}

Jensen e Meckling (1976, p.310) definem uma relação de agência "como um contrato onde uma ou mais pessoas - o principal - emprega uma outra pessoa - o agente - para realizar algum serviço ou trabalho em seu favor, envolvendo a delegação de alguma autoridade de decisão para o agente". Dessa relação, originam-se conflitos, em essência, devido: 1) à separação entre controle e propriedade: Berle e Means (1932) enfatizam que a pulverização da propriedade 
fortalece o poder dos gestores para agir em seus próprios interesses e não no interesse dos acionistas; 2) à inexistência de contrato completo: Klein (1983) afirma que os contratos perfeitos e completos, abrangendo todas as contingências e as respostas às mudanças e aos desafios do ambiente de negócios, simplesmente não existem, devido ao grande número de contingências possíveis, à multiplicidade de reações às contingências e à crescente freqüência com que as contingências imprevisíveis passaram a ocorrer - dessa feita, outorgam-se aos gestores, mais do que a execução de ações previsíveis, o direito residual de controle da empresa; 3) à inexistência de agente perfeito: a natureza humana é utilitarista e racional, conduzindo os indivíduos a maximizarem uma função utilidade mais para as suas próprias preferências e os seus próprios objetivos.

De acordo com Andrade e Rossetti (2004, p.103), o desalinhamento entre os interesses dos principais e os dos agentes, levam à ocorrência de duas diferentes categorias de custos de agência: 1) custos atribuíveis ao oportunismo dos gestores; e 2) custos incorridos pelos acionistas para o controle da gestão. Entretanto, os custos originários dos conflitos de agência não ocorrem apenas entre controladores e gestores, mas também entre acionistas minoritários e acionistas majoritários. Esse último conflito origina-se devido à assimetria de direitos resultantes da existência de mais de uma classe de votos ou do uso discricionário do poder exercido pelos majoritários em detrimento dos interesses dos minoritários (ANDRADE e ROSSETTI, 2004, p. 107). Na verdade, como encontram La Porta et al (1998 e 1999), esse é o principal conflito de agência existente na maioria dos países, inclusive no Brasil.

Com existência de custos decorrentes dos conflitos de agência, torna-se necessário estabelecer mecanismos de controle ex-ante para que o processo de governança corporativa institua-se de forma a alinhar os interesses das partes envolvidas e minimizar os custos ex-post. Os mecanismos de controle estabelecidos sintetizam os resultados de todas as formas de ativismo por boas práticas de governança e são resultados da reação de agentes que se consideram "traídos em seus direitos por conflitos de interesses, por oportunismo perversos, por juízos gerenciais orientados para objetivos dos próprios gestores, pelas variadas formas de expropriação e pela inexistência de monitoramentos eficazes" (ANDRADE e ROSSET'TI, 2004, p.114).

Os mecanismos de controle podem ser classificados em duas categorias: interno e externo. Os mecanismos internos são aqueles instituídos no ambiente interno da empresa, e os externos instituídos pelo mercado como um todo (ambiente externo). Em síntese, citam-se os seguintes mecanismos de controle internos: estrutura de propriedade, estrutura de capital, conselhos de administração, sistema de remuneração dos executivos, monitoramento compartilhado e estrutura multidivisional de negócios. Os mecanismos externos de controle podem ser sumariados nos seguintes desdobramentos: ambiente legal e regulatório, padrões contábeis exigidos, controle pelo mercado de capitais, pressões de mercados competitivos, ativismo de investidores institucionais e ativismo de acionistas. Rogers (2006) resume os diferentes mecanismos internos e externos de governança corporativa e seus desdobramentos no Brasil, evidenciando vários trabalhos que abordaram o tema (Quadro 1).

Diante da importância do tema, vários esforços têm sido empreendidos na sociedade brasileira com vista a melhorar as práticas de governança corporativa adotadas pelas empresas. Em 2001 foi instituída a Lei 10.303, que busca uma reforma da Lei das Sociedades Anônimas cujo objetivo essencial era uma maior proteção dos acionistas minoritários. Alguns códigos de melhores práticas de governança têm sido editados por agentes importantes do mercado de capitais, tais como: códigos de boas práticas de governança corporativa do Instituto Brasileiro de Governança Corporativa (IBGC), Associação Nacional dos Bancos de Investimentos (ANBID) e do fundo de pensão PREVI do Banco do Brasil, além das recomendações da Comissão de Valores Mobiliários (CVM) sobre governança corporativa. A principal atuação no sentido de buscar melhores práticas de governança corporativa foi a instituição, pela Bovespa, no final de 2000, do Novo Mercado e dos Níveis Diferenciados de Governança Corporativa (auto-regulação). As empresas que se comprometeram, voluntariamente, através desse contrato privado, a adotarem padrões de governança corporativa superiores, foram indexadas no Índice de Governança Corporativa (IGC) da Bovespa, que passou a ser calculado a partir de junho de 2001. Em síntese, tal índice comporta uma carteira de empresas que se comprometeram voluntariamente a adotarem melhores padrões de governança corporativa. Por ir ao encontro dos objetivos da presente pesquisa, a próxima seção tratará do Novo Mercado e dos Níveis Diferenciados de Governança Corporativa por ser esse o principal mecanismo externo de controle pelo mercado de capitais no Brasil.

\section{O NOVO MERCADO E OS NÍVEIS DIFERENCIADOS DA BOVESPA}

O Novo Mercado e os Níveis Diferenciados de Governança Corporativa da Bovespa foram inspirados no Neuer Markt alemão. A vantagem do Neuer Markt foi que não necessitou de uma reforma da legislação e, portanto, não afetou a situação das empresas que já eram abertas e queriam continuar listadas nos mercados tradicionais. Por meio de um contrato privado voluntário, as empresas aderiram a regras que exigem a adoção de práticas corporativas superiores, fazendo com que, de fato, o Novo Mercado e os Níveis Diferenciados de Governança Corporativa funcionem como um selo de qualidade cujo valor reside nas 


\begin{tabular}{|c|c|c|c|}
\hline \multicolumn{2}{|c|}{ Mecanismos } & \multirow{2}{*}{$\begin{array}{c}\text { Questões } \\
\begin{array}{c}\text { Relacionadas no } \\
\text { Brasil }\end{array} \\
\text { Nova Lei das S/As. } \\
\end{array}$} & \multirow{2}{*}{$\begin{array}{c}\text { Evidências Empíricas e Trabalhos que Abordam as } \\
\text { Questões } \\
\text { Barros et al. (2000), Gorga (2004), Rodrigues e Mendes } \\
\text { (2004), Teixeira (2004) }\end{array}$} \\
\hline \multirow{11}{*}{$\begin{array}{l}\text { Mecanismos } \\
\text { Externos }\end{array}$} & \multirow{3}{*}{$\begin{array}{l}\text { Ambiente Legal e } \\
\text { Regulatório }\end{array}$} & & \\
\hline & & $\begin{array}{l}\text { Nova Lei de } \\
\text { Falências }\end{array}$ & Rogers (2003), Teixeira (2004) \\
\hline & & $\begin{array}{l}\text { Incentivos para os } \\
\text { Fundos de Pensão }\end{array}$ & Vieira e Corrêa (2002) \\
\hline & $\begin{array}{l}\text { Padrões Contábeis } \\
\text { Exigidos }\end{array}$ & $\begin{array}{l}\text { Melhor Evidenciação } \\
\text { e Padronização } \\
\text { Internacional } \\
\text { (disclosure }) \\
\end{array}$ & $\begin{array}{l}\text { Bergamini Jr. (2002), Quinteiro (2004), Dantas, Zendersky } \\
\text { e Niyama (2004), Rodrigues, Silveira e Silveira (2004), } \\
\text { Haussmann et al. (2004), Leal e Carvalhal-da-Silva (2005) }\end{array}$ \\
\hline & \multirow[t]{2}{*}{$\begin{array}{l}\text { Controle Pelo } \\
\text { Mercado de } \\
\text { Capitais }\end{array}$} & $\begin{array}{l}\text { Níveis Diferenciados } \\
\text { de Governança da } \\
\text { Bovespa (Análise do } \\
\text { IGC) }\end{array}$ & $\begin{array}{l}\text { Comerlato, Terra e Braga (2002), Srour (2002), Coutinho, } \\
\text { Oliveira e Da Motta (2003), Carvalho (2003), Lima e } \\
\text { Terra (2004), Batistella et al. (2004), Aguiar, Corrar e } \\
\text { Batistella (2004), Vieira e Mendes (2004), Lima et al. } \\
\text { (2004), Alencar e Lopes (2005), Rogers, Ribeiro e Sousa } \\
\text { (2005a e 2005b), Lameira, Ness Jr e Da Motta (2005), } \\
\text { Caselani e Eid Jr (2005), Lameira, Ness Jr e Soares (2005) }\end{array}$ \\
\hline & & $\begin{array}{c}\text { American Depositary } \\
\text { Receipts (ADR's) }\end{array}$ & $\begin{array}{c}\text { Rodrigues (1999), Costa Jr et al. (2000), Srour (2002), } \\
\text { Garcia e Bertucci (2002), Silveira, Barros e Famá (2003), } \\
\text { Bruni e Famá (2003), Garcia, Sato e Caselani (2004) }\end{array}$ \\
\hline & \multirow{3}{*}{$\begin{array}{l}\text { Pressões de } \\
\text { Mercados } \\
\text { Competitivos }\end{array}$} & Mercado da Empresa & Andrade e Rossetti (2004) \\
\hline & & $\begin{array}{l}\text { Mercado de Trabalho } \\
\text { dos Executivos }\end{array}$ & $\begin{array}{l}\text { Carmona e Santana (2002), Oliveira, Basso e Nakamura } \\
\text { (2004) }\end{array}$ \\
\hline & & $\begin{array}{l}\text { Agências } \\
\text { de Rating }\end{array}$ & Andrade e Rossetti (2004) \\
\hline & \multicolumn{2}{|c|}{$\begin{array}{l}\text { Ativismo de Investidores } \\
\text { Institucionais }\end{array}$} & Cia, Guarita e Cia (2002) \\
\hline & $\begin{array}{l}\text { Ativismo de } \\
\text { Acionistas }\end{array}$ & $\begin{array}{l}\text { Códigos de Melhores } \\
\text { Práticas }\end{array}$ & $\begin{array}{l}\text { IBGC (2004), CVM (2002), ANBID (2005) e PREVI } \\
(2005)\end{array}$ \\
\hline \multirow[t]{3}{*}{$\begin{array}{l}\text { Mecanismos } \\
\text { Internos }\end{array}$} & \multirow{3}{*}{$\begin{array}{l}\text { Estrutura de } \\
\text { Propriedade }\end{array}$} & $\begin{array}{c}\text { Grau de } \\
\text { Concentração }\end{array}$ & $\begin{array}{l}\text { Siqueira (1998), Valadares e Leal (2000), Carvalhal-da- } \\
\text { Silva (2002), Saito (2002), Okimura (2003), Carvalhal-da- } \\
\text { Silva (2004), Silveira et al. (2004), Okimura, Silveira e } \\
\text { Rocha (2004), Silveira, Barros e Fama (2004), Leal et al. } \\
\text { (2000), Leal e Saito (2003), Carvalhal-da-Silva e Leal } \\
\text { (2005), Silveira, Belatto e Barros (2005) }\end{array}$ \\
\hline & & $\begin{array}{l}\text { Identidade dos } \\
\text { Controladores }\end{array}$ & $\begin{array}{c}\text { Siffert Filho (1998), Siqueira (1998), Rabelo e Silveira } \\
\text { (1999), Rabelo e Coutinho (2001), Okimura (2003), Leal e } \\
\text { Saito (2003), Carvalhal-da-Silva (2004), Okimura, Silveira } \\
\text { e Rocha (2004) }\end{array}$ \\
\hline & & Controle Indireto & $\begin{array}{l}\text { Valadares e Leal (2000), Leal et al. (2000), Rabelo e } \\
\text { Coutinho (2001), Procianoy (2002), Carvalhal-da-Silva } \\
\text { (2002), Leal e Saito (2003), Carvalhal-da-Silva (2004) }\end{array}$ \\
\hline
\end{tabular}

Quadro 1: Mecanismos interno e externo de Governança corporativa no Brasil

Fonte: Rogers (2006). 
obrigações contratuais assumidas pela empresa e na maneira como a Bovespa administra tais contratos (CARVALHO, 2002, p.27).

Dessa forma, há 4 mercados (ou quatro selos): mercado tradicional, Nível 1, Nível 2 e Novo Mercado - aumentando o grau de exigência à medida que se sobe de um mercado para outro. De acordo com a Bovespa (2002, p.5), as principais práticas exigidas para inserção no Nível 1 são:

- manutenção em circulação de uma parcela mínima de ações (free float), representando $25 \%$ do capital;

- realização de ofertas públicas de colocação de ações por meio de mecanismos que favoreçam a dispersão do capital;

- melhoria nas informações prestadas trimestralmente, entre as quais a exigência de consolidação e de revisão especial;

- cumprimento de regras de transparência em operações envolvendo ativos de emissão da companhia por parte de acionistas controladores ou administradores da empresa;

- divulgação de acordos de acionistas e programas de opções de ações (stock options);

- disponibilização de um calendário anual de eventos corporativos.

Além de adotar as práticas do Nível 1, as companhias do Nível 2 se comprometem a adotar um conjunto mais amplo de práticas de governança e de direitos adicionais para os acionistas minoritários, entre os quais:

- mandato unificado de um ano para todo o Conselho de Administração;

- disponibilização de balanço anual seguindo as normas do US GAAP ou IASB;

- extensão para todos os acionistas detentores de ações ordinárias das mesmas condições obtidas pelos controladores quando da venda do controle da companhia e de, no mínimo, $70 \%$ deste valor para os detentores de ações preferenciais (tag along);

- direito de voto às ações preferenciais em algumas matérias, como transformação, incorporação, cisão e fusão da companhia e aprovação de contratos entre a companhia e empresas do mesmo grupo;

- obrigatoriedade de realização de uma oferta de compra de todas as ações em circulação, pelo valor econômico, nas hipóteses de fechamento do capital ou cancelamento do registro de negociação neste Nível;

- adesão à Câmara de Arbitragem para resolução de conflitos societários.

No Novo Mercado, as empresas, além de se comprometerem com a adoção de todas as exigências do Nível 2, devem emitir apenas ações ordinárias. Nesse sentido, a proposta da Bovespa é possibilitar que as empresas comprometidas com maior transparência e melhores práticas de governança corporativa tenham uma maior valorização de suas ações.

Desde a criação do Novo Mercado e dos Níveis 1 e 2 de Governança Corporativa da Bovespa, e com o início do cálculo do IGC, em Junho de 2001, algumas pesquisas empíricas, como relatadas adiante, têm buscado analisar a performance deste índice e das empresas participantes em relação aos outros índices da Bovespa e empresas. O objetivo geral de tais pesquisas tem se concentrado em comparar as empresas com melhores práticas de governança, inseridas na carteira do IGC, em relação àquelas com práticas de governança corporativas inferiores, incorporadas nos outros índices. Levando em consideração que o IGC é formado por uma carteira de empresas que adotam práticas de governança corporativa superiores, esses estudos buscam, em essência, testar a eficácia de tais práticas para o mercado de capitais nacional. No geral, a performance comparativa dos índices da Bovespa é analisada em relação a quatro aspectos: 1) retorno e valor; 2) liquidez; 3) custo de captação; e 4) risco (volatilidade). Em essência, busca-se evidenciar se as empresas com melhores práticas de governança apresentaram maior retorno e valor, maior liquidez, menor custo de captação e menor risco. $\mathrm{Na}$ seção subseqüente, objetiva-se apresentar evidências empíricas que analisaram a performance de empresas participantes do IGC nos quatros aspectos supracitados.

\section{AVALIAÇÃO DA PERFORMANCE DAS PRÁTICAS DE GOVERNANÇA CORPORATIVA PELO IGC}

\subsection{Governança corporativa, retorno e valor das ações.}

Comerlato, Terra e Braga (2002) estudaram se houve uma reação positiva do mercado de capitais brasileiro à adesão de dez empresas de capital aberto ao Nível 1. Os autores aplicaram a metodologia do estudo de eventos conduzida em três diferentes tamanhos de janela, sendo a data base a adesão oficial em 26/06/2001 dessas empresas ao Nível 1. De acordo com o trabalho dos autores, a reação do mercado de ações nacional à adesão formal de dez empresas ao Nível 1 foi, em média, estatisticamente insignificante, indicando o não reconhecimento, pelo mercado de capitais brasileiro, das novas regras de governança corporativa como suficientes para causar um efeito significativo nos retornos das ações dessas empresas. Salientam Comerlato, Terra e Braga (2002) que, apesar de estatisticamente insignificante, há indícios de que a avaliação do mercado em relação ao Nível 1 é, em princípio, positiva.

Nesse mesmo sentido, Coutinho, Oliveira e Da Motta (2003) fizeram uma análise comparativa entre as rentabilidades do IGC e de dois outros índices de mercado - Ibovespa e IBrX-100. Para que pudesse ser feita a comparação entre as rentabilidades do IGC e dos outros índices, foram coletados os fechamentos semanais dos três índices num período de 83 semanas (de 06/07/2001 a 31/01/2003) e aplicado o Capital Assets Price Model (CAPM). Os autores encontraram alfas de Jensen positivos, indicando um retorno ajusta- 
do ao risco do IGC superior ao Ibovespa e ao IBrX-100 no período do estudo, embora não tenham apresentado significância estatística. Concluem que, de forma inicial, a carteira composta por ações de empresas com níveis de governança diferenciados demonstra uma rentabilidade superior, podendo ser "indício de que é vantajoso para o investidor dar preferência a empresas que se preocupam e comprometem com boas práticas de governança corporativa" (COUTINHO, OLIVEIRA e DA MOTTA, 2003, p.13).

De outro lado, Carvalho (2003), aplicando a metodologia de estudo de evento, encontra resultados estatisticamente significativos em relação aos retornos de empresas que migraram para algum nível de governança da Bovespa até Maio de 2002. Segundo o autor, a migração teve impacto sobre a valorização das ações (existência de retornos anormais positivos). Seguindo a mesma metodologia do estudo de eventos, Lima e Terra (2004) analisaram a significância estatística dos retornos anormais para oito grupos de empresas, entre as quais: empresas com governança corporativa na Bovespa (empresas participantes do IGC) e empresas pontuais na entrega das demonstrações financeiras, empresas estas que os autores consideraram como sinalizador de boas práticas de governança corporativa. Os resultados empíricos da pesquisa revelaram que os investidores reagem de forma diferenciada a alguns sinalizadores de boas práticas de governança corporativa, percebendo retornos anormais significativos para empresas pontuais na divulgação. Entretanto, em relação ao grupo de empresas pertencentes ao IGC, Lima e Terra (2004) não encontraram retornos anormais positivos estatisticamente significantes.

Batistella et al. (2004), também utilizando a metodologia de estudo de eventos, analisaram se empresas que adotaram algum nível do Novo Mercado da Bovespa até Junho de 2003 apresentaram retornos anormais positivos em um curto espaço de tempo. Os autores verificaram que a presença de retornos anormais positivos nos preços das ações não é estatisticamente superior aos retornos anormais negativos, o que indica que provavelmente não ocorreu uma maior valorização das companhias que adotaram diferenciadas práticas de governança corporativa.

Comparando o preço médio das ações de observações anteriores à implementação do Nível 1 de Governança Corporativa da Bovespa com outras posteriores, Aguiar, Corrar e Batistella (2004) aceitam a hipótese, para as observações analisadas, de que não houve mudanças significativas no preço médio das ações negociadas para empresas que se adaptaram ao Nível 1 de Governança da Bovespa.

Em oposição a essa conclusão, Andrade e Rossetti (2004, p.300) apresentam as séries históricas da Tabela 1, onde afirmam que a migração para os níveis diferenciados de governança da Bovespa teve impactos significativamente positivos sobre a valorização das ações. Em dezembro de 2003, em relação a dezembro de 2001, a valorização das ações medida pelo IBO foi de $64 \%$, enquanto que a valorização das ações de empresas que compõem o índice IGC foi de $83 \%$. Rogers, Ribeiro e Sousa (2005), fazendo a mesma análise de Andrade e Rossetti (2004, p.300), porém abrangendo a comparação para Julho de 2005, concluem que em Julho de 2005, em relação a dezembro de 2001, a valorização das ações medida pelo IBO foi de $89,35 \%$, enquanto que a valorização das ações de empresas que compõem o índice IGC foi de 157,60\%.

Com o objetivo de melhor avaliar o impacto das práticas de governança, Vieira e Mendes (2004) estabeleceram um critério, utilizando as carteiras estáticas dos índices IBrX100, IBrX-50 e Ibovespa, válidas de setembro a dezembro de 2004, extrapolando-as para o período de junho de 2001 - setembro de 2004. O objetivo dessa metodologia, segundo os autores, é que existem muitas empresas que participam de dois ou mais índices, carecendo assim de uma análise que separe a influência de cada empresa. Os resultados obtidos a partir dessa análise mostram uma rentabilidade muito superior do grupo de empresas associadas a boas práticas de governança, conforme se evidencia na Tabela 2. A partir dessa tabela, nota-se que a rentabilidade total de cada índice é influenciada positivamente pelas ações de empresas com práticas de governança corporativa.

Tabela 1: Evolução Comparativa dos Índices IBO e IGC

\begin{tabular}{ccccc}
\hline \multirow{2}{*}{ Períodos } & \multicolumn{2}{c}{ Índices nominais } & \multicolumn{2}{c}{ Evolução } \\
\cline { 2 - 5 } & Ibovespa & IGC & Ibovespa & IGC \\
\hline Dez./01 & 13.577 & 1.010 & 100 & 100 \\
Dez./02 & 11.268 & 1.026 & 83 & 102 \\
Jan./03 & 10.941 & 980 & 81 & 97 \\
Fev. & 10.280 & 994 & 76 & 98 \\
Mar. & 11.273 & 1.095 & 83 & 108 \\
Abr. & 12.556 & 1.165 & 92 & 115 \\
Maio & 13.421 & 1.214 & 99 & 120 \\
Jun. & 12.972 & 1.159 & 96 & 115 \\
Jul. & 13.571 & 1.263 & 100 & 125 \\
Ago. & 15.174 & 1.406 & 112 & 139 \\
Set. & 16.010 & 1.359 & 118 & 135 \\
Out. & 17.982 & 1.464 & 132 & 145 \\
Nov. & 20.183 & 1.613 & 149 & 160 \\
Dez. & 22.236 & 1.845 & 164 & 183 \\
\hline
\end{tabular}

Fonte: Andrade e Rossetti (2004, p.300)

Lameira, Ness Jr. e Soares (2005) compartilham resultados de uma pesquisa que procurou verificar se a melhoria das práticas de governança corporativa já promoveu impacto no valor das empresas mensurado pelo valor de mercado dos ativos ou market value of assets (MVA) e pelo Q de Tobin. Adotaram como método estatístico regressão linear múltipla, que foi aplicada em uma base de dados retirada da Economática ${ }^{\circledR}$. Os autores concluem, pela significância de uma variável dummy de participação no Novo Mercado em um dos modelos que foi inserida a variável Q de Tobin 
como dependente, que a melhoria de práticas de governança corporativa já promoveu impacto no valor das companhias abertas listadas em bolsa cujas ações apresentem liquidez e volatilidade de preços.

Tabela 2: Variação dos Índices entre 25/06/01 a 13/09/04 (\%)

\begin{tabular}{lcccc}
\hline & Ibovespa & IBrX-10 & IBrX-50 & IGC \\
\hline $\begin{array}{l}\text { Variação do Índice assumindo } \\
\text { carteira de ações fixa no período }\end{array}$ & 123,49 & 185,39 & 164,84 & 207,91 \\
\hline $\begin{array}{l}\text { Participação das ações com } \\
\text { práticas de governança no índice }\end{array}$ & 24,84 & 45,04 & 45,98 & 100 \\
\hline $\begin{array}{l}\text { Variação das ações com práticas } \\
\text { de governança no índice }\end{array}$ & 292,07 & 221,31 & 225,60 & 207,91 \\
\hline $\begin{array}{l}\text { Variação das ações sem práticas } \\
\text { de governança no índice }\end{array}$ & 67,78 & 155,95 & 113,12 & 0,00 \\
\hline
\end{tabular}

Fonte: Vieira e Mendes (2004, p.113).

\subsection{Governança corporativa e liquidez das ações}

Carvalho (2003), Aguiar, Corrar e Batistella (2004) e Vieira e Mendes (2004) também analisaram a liquidez das ações que compõem o índice IGC em relação às ações dos outros índices da Bovespa. Carvalho (2003) reporta que com a migração para os níveis diferenciados de governança da Bovespa, houve um aumento médio no volume diário transacionado das ações após a migração. Esse fato, segundo o autor, significa um aumento de liquidez após a migração, permitindo concluir que os preços das ações participantes dos níveis diferenciados passaram a responder menos ao volume transacionado.

Aguiar, Corrar e Batistella (2004) examinaram se a quantidade média e o volume médio de ações negociadas das empresas que se adaptaram ao Nível 1 da Bovespa sofreram mudanças significativas após essa ação, rejeitando os autores essa hipótese. Segundo Aguiar, Corrar e Batistella (2004, p.346), “(...) as empresas que migraram para o Nível 1 de Governança Corporativa não apresentaram mudanças significativas na quantidade média de ações negociadas (...), não sofreram mudanças significativas no volume médio (em R\$) de ações negociadas (...)".

Vieira e Mendes (2004), analisando a liquidez das ações do Ibovespa, IBrX-100, IBrX-50 e IGC por meio do índice dado pelo sistema Economática ${ }^{\circledR}$, verificaram que o Ibovespa foi o mais líquido para o período entre 25/06/01 a 13/08/04, enquanto o IGC foi o que apresentou a menor liquidez. Todavia, concluem os autores que esse fato, conjuntamente com o bom desempenho do IGC, reflete um perfil de mais longo prazo dos investidores desse grupo de ações.

Tabela 3: Relação entre o Valor da Ação

Fonte: Vieira e Mendes (2004, p.114).

\subsection{Governança corporativa e custo de captação}

Lima et al. (2004) verificaram se o custo de captação via debêntures no mercado de capitais brasileiro é menor para empresas que aderiram ao Novo Mercado, buscando identificar se o argumento de que o custo de capital reduz em decorrência da adoção de boas práticas de governança corporativa é valido ou não. Analisando a emissão de debêntures de janeiro de 2000 a dezembro de 2003 para empresas que faziam parte do Ibovespa e aderiram ao Novo Mercado, os autores não encontraram evidência que suportasse qualquer diferencial nos custos de captação via debêntures, seja por uma empresa que tenha aderido ao Novo Mercado ou por uma empresa que não tenha aderido.

De outro lado, Vieira e Mendes (2004) expandindo suas análises, calcularam a relação existente entre valor da ação e o lucro líquido por ação, conforme a Tabela 3. De acordo com os autores, nota-se que as empresas presentes no IGC apresentaram uma superioridade representativa em relação aos outros índices quando se trata de avaliar o preço da ação em relação ao lucro líquido. "Tal resultado vai na direção das conclusões existentes sobre o assunto, as quais afirmam que as práticas de governança são capazes de reduzir o custo de captação das empresas" (VIEIRA e MENDES, 2004, p.113). Além do mais, Vieira e Mendes (2004), avaliando os resultados da Tabela 3 a partir de uma decomposição do IGC nos diversos níveis de governança, encontraram que no Novo Mercado a relação preço/lucro líquido foi de 57,42, no Nível 2 foi de 36,41 e no Nível 1 foi de 20,02, o que corrobora um prêmio positivamente correlacionado com o grau de governança. e o Lucro Liquido por Ação (25/06/01 a 13/09/04) o dos Índices entre 25/06/01 a 13/09/04 (\%)

\begin{tabular}{lcccc}
\hline & Ibovespa & IBrX-10 & IBrX-50 & IGC \\
\hline $\begin{array}{l}\text { Preço/Lucro = Cotação/(Lucro Líquido/ } \\
\text { Qtd Total de Ações Calculada) }\end{array}$ & 15,66 & 16,81 & 15,40 & 22,68 \\
\hline
\end{tabular}


governança corporativa) não afeta o custo de capital. Alencar e Lopes (2005), reforçando os resultados, corroboram que a implementação de práticas diferenciadas de governança corporativa, evidenciadas pela indexação da empresa no IGC, não resultou em alteração do custo de capital.

\subsection{Governança corporativa e volatilidade das ações}

Os estudos que fazem a análise comparativa do IGC em relação aos outros índices de bolsa, no que concerne ao aspecto risco, são direcionados de duas formas: a) os que analisam o risco individual de cada índice medido pela variabilidade de seus retornos; e b) os que examinam a sensibilidade dos preços das ações (retornos) em relação a riscos externos, essencialmente a fatores macroeconômicos.

Em relação à primeira forma, Vieira e Mendes (2004) mostraram que para o período entre 25/06/01 e 13/08/04 o IGC apresentou volatilidade anual maior do que os índices IBrX-50 e IBrX-100. Os autores ressaltaram que o Ibovespa apresentou uma maior volatilidade anual, muito influenciada pelas ações do setor de telecomunicações, e que não encontraram qualquer explicação que justificasse a maior volatilidade do IGC em relação aos índices IBrX. "Por outro lado, os testes mostraram que o IGC apresenta a maior rigidez quando se trata de retornos negativos, ou seja, as ações se comportam de maneira mais estável diante de tendências de baixa" (VIEIRA e MENDES, 2004, p.115).

Procedendo a análise da variabilidade individual dos índices IGC e Ibovespa, Rogers, Ribeiro e Sousa (2005) calcularam o coeficiente de variação para o período de Junho de 2001 a Agosto de 2004, usando a média mensal dos fechamentos diários. Para esse período, os autores encontraram um coeficiente de variação de $29,43 \%$ para o Ibovespa e $28,85 \%$ para o IGC. Rogers (2006) complementa, porém expandindo a amostra até Julho de 2005 e usando as médias mensais do índice médio diário, que os coeficientes de variação são, respectivamente, para Ibovespa e IGC, 34,06\% e 39,99\%. Considerando apenas a variação negativa dos retornos mensais, o coeficiente de variação do Ibovespa é de $-103,60 \%$ e do IGC $-137,20 \%$. Para a variação positiva dos retornos, esse valor é de $67,81 \%$ e $64,78 \%$, respectivamente para o Ibovespa e IGC.

Também estudando a variabilidade dos retornos, Lameira, Ness Jr e Da Motta (2005) verificaram se as melhores regras de governança corporativa têm promovido impacto na percepção do risco da empresa observado pelo mercado. Os autores analisaram o risco em dois períodos, um anterior ao advento dos níveis diferenciados de governança corporativa, e outro posterior à criação dos níveis diferenciados de governança. Lameira, Ness Jr e Da Motta (2005) concluíram que já existem evidências de que a prática de melhores regras de governança impactaram risco das companhias abertas brasileiras sem, entretanto, encontra- rem relação de causalidade entre a melhoria dessas práticas e os riscos antes e depois.

No que concerne à análise dos índices a riscos externos, são quatro os estudos mais recentes: Srour (2002), Carvalho (2003), Rogers (2006) e Caselani e Eid Jr (2005). Srour (2002) investigou se o grupo diferenciado de governança da Bovespa foi relevante para uma menor diluição dos acionistas minoritários e para uma performance diferenciada da firma em momentos de choques de retornos, especialmente na Crise de 11 de Setembro. Com os testes realizados, o autor confirma efeito positivo encontrado sobre a importância deste tipo de contrato em momentos de crise. Empresas pertencentes ao Nível 1 da Bovespa tiveram um retorno superior de aproximadamente $6 \%$ no período da Crise de 11 de Setembro, concluindo assim Srour (2002), que melhores práticas de governança corporativa tendem a diminuir a volatilidade do retorno das firmas diante de um choque negativo.

Carvalho (2003) encontrou evidências empíricas da redução à exposição a fatores macroeconômicos para as empresas que migraram para os níveis de governança da Bovespa. De acordo com o autor:

$$
\begin{aligned}
& \text { o comprometimento com melhores práticas por } \\
& \text { meio da migração tem impacto sobre a valorização } \\
& \text { das ações (existência de retornos anormais positivos), } \\
& \text { aumenta o volume de negociação, aumenta a liquidez } \\
& \text { e reduz a sensibilidade do preço das ações a fatores } \\
& \text { macroeconômicos (CARVALHO, 2003, p.13). }
\end{aligned}
$$

No que se refere à redução da sensibilidade do preço das ações a fatores macroeconômicos por parte das empresas que aderiram aos níveis diferenciados de governança, Carvalho (2003) salienta que devemos ser um pouco cautelosos nesse ponto, uma vez que os testes conduzidos pelo autor apresentaram significância estatística em apenas uma análise. Ademais, para desenvolver o seu estudo, o autor usa exclusivamente a variável câmbio para identificar a volatilidade (exposição a fatores macroeconômicos) das ações de empresas que migraram para os níveis diferenciados da Bovespa.

Rogers (2006) fez uma análise abrangente, comparando o IGC e o Ibovespa frente a exposição aos seguintes fatores macroeconômicos: Câmbio, Risco Brasil, Índice Dow Jones, proxy do Produto Interno Bruto (crescimento econômico) e Taxa de Juros SELIC. O autor calculou as elasticidades de longo prazo dos índices Ibovespa e IGC em relação a cada um desses fatores que a literatura indica como os principais que influenciam o mercado de capitais. Estudando o período de Julho de 2001 a Agosto de 2005, Rogers (2006) encontrou que o IGC é menos sensível em relação a todos os fatores macroeconômicos indicados, exceto em relação à proxy do Produto Interno Bruto cujo IGC mostrou-se mais sensível. Ademais, conclui o autor que o conjunto de fatores macroeconômicos é melhor para explicar o 
Ibovespa do que o IGC, indicando redução da exposição a riscos externos por parte de empresas que praticam melhores práticas de governança corporativa.

De outro modo, Caselani e Eid Jr (2005) modelaram as volatilidades das ações mais líquidas negociadas na Bovespa no período de Janeiro de 1995 a Setembro de 2003 como sendo determinadas: pelas volatilidades das ações no período anterior; pela alavancagem financeira; pelo preço da ação; pelo giro da ação; pela taxa de juros real; pela capitalização de mercado da empresa; pelo índice Dow Jones industrial; e pelo Produto Industrial Bruto. Para o período de existência do IGC, os autores incluíram uma variável dummy caso a empresa fosse participante dos níveis diferenciados de governança da Bovespa, encontrando uma relação negativa estatisticamente significante entre a volatilidade e essa variável dummy. Caselani e Eid Jr (2005) concluíram que as companhias que aderiram às boas práticas de governança conseguiram obter uma redução na volatilidade dos retornos de seus papéis.

\section{AVALIAÇÃO DA PERFORMANCE DAS PRÁTICAS DE GOVERNANÇA CORPORATIVA POR ADR'S}

Outra maneira que alguns estudos empregaram para verificar a performance das boas práticas de governança corporativa foi mediante a análise de empresas que emitem ADR's. Admite-se que empresas possuidoras de ADR's apresentam práticas de governança corporativa superiores em decorrência das exigências da Securities and Exchange Commission (SEC) para o lançamento de títulos de empresas brasileiras no mercado norte-americano. Essas empresas, através da emissão de ADR's, buscam: reduzir o custo de capital, aumentar a liquidez das ações, expandir a base de acionistas, e utilizar as ações na implementação de fusões e aquisições internacionais. A listagem em mercado de capitais internacional e a submissão a estruturas regulatórias que exigem maior nível de governança corporativa aumentam a visibilidade da empresa, o que, por conseguinte, pode influenciar positivamente o valor das ações.

Da mesma forma, como nos estudos que comparam os índices da Bovespa, as pesquisas empíricas que investigam a performance de empresas que emitiram ADR's têm sido direcionadas em relação a três principais aspectos: retorno e valor das ações, liquidez e risco (volatilidade). Um dos primeiros trabalhos, analisando as empresas emitentes de ADR's no Brasil pós-estabilização da economia, foi Costa Jr et al. (2000). Através de um estudo de eventos da data do início da emissão de ADR's, os autores examinaram o efeito sobre o retorno, volatilidade e liquidez das ações de sete empresas brasileiras. Os resultados encontrados indicaram inexistência de retornos anormais e alterações no valor das companhias, porém verificou-se que houve uma signi- ficativa redução da volatilidade e aumento da liquidez das ações após o início da negociação das ADR's.

Com essa mesma metodologia, Rodrigues (1999), num estudo mais abrangente, analisou a evolução de 31 empresas brasileiras que emitiram ADR's durante o período de um ano antes e um ano após a época da listagem. O estudo analisou os retornos, a liquidez, o volume e a volatilidade da negociação das ações da amostra no mercado brasileiro, encontrando os seguintes resultados após a listagem: a) houve retornos anormais negativos; b) redução da volatilidade; e c) aumento da liquidez e do volume relativo negociado. $\mathrm{O}$ autor concluiu que as empresas, com a emissão de ADR's, passam a dispor de preços mais justos e menor risco pelas suas ações com a ampliação das alternativas de obtenção de recursos, minimizando assim o custo de acesso aos recursos e, conseqüentemente, reduzindo seu custo de capital.

Srour (2002) enfoca o relacionamento existente entre práticas de governança e a emissão de ADR's. Segundo o autor, as empresas brasileiras emissoras de ADR's do nível 1, que por suas características não são obrigadas a adequar às regras de governança exigidas pelo órgão regulador do mercado de capitais norte-americano, não experimentaram modificações relevantes na performance de suas ações após a emissão dos recibos em momentos de choque de retornos, como na Crise Asiática, desvalorização do real e a Crise de 11 de Setembro. De outro modo, empresas brasileiras emissoras de ADR's do nível II e III, cujas exigências em termos de adequação aos critérios de governança da Securities and Exchange Commission são maiores, experimentaram uma melhor performance nos choques de retornos negativos.

Silveira, Barros e Famá (2003) analisaram aspectos da dinâmica dos retornos e volatilidade de ações de 31 empresas brasileiras que emitiram ADR's na década de 1990. Testaram três hipóteses presentes na literatura de finanças: 1) a emissão de ADR's é seguida de diminuição nos retornos médios, refletindo uma redução no custo de capital próprio da empresa emitente; 2) redução da volatilidade dos retornos; e 3) o relacionamento entre o retorno esperado e seu desvio padrão deve se enfraquecer após a emissão das ADR's, em virtude da negociação dos recibos se realizar num mercado mais eficiente. Modelando os retornos em períodos anteriores e posteriores ao registro das ADR's, os autores apontam conclusões estatisticamente não categóricas, porém os resultados indicam algum suporte às hipóteses consideradas.

Aumentando o escopo da amostra, Bruni e Famá (2003) testaram para 43 ações negociadas na Bovespa se os lançamentos de ADR's provocaram uma redução do custo de capital total das empresas e influenciaram a presença de retornos anormais nos preços das ações. Empregaram a metodologia de estudo de eventos usando três janelas: 12, 24 e 36 meses anteriores e posteriores ao anúncio de lançamento, com o intuito de mensurar diferenças nos custo de capital e retornos anormais. Das 43 empresas analisadas, 70\% apre- 
sentaram redução do custo de capital na janela 36; 60\% na janela 24; e $61 \%$ na janela 12 , rejeitando a hipótese de que o custo de capital das empresas emissoras de ADR's mantémse inalterado após o lançamento do programa.

Em relação aos retornos anormais, Bruni e Famá (2003) encontraram suas presenças analisando um período de 30 meses anteriores e 30 meses posteriores ao evento. Fazendo ainda uma análise de 50 dias antes e 50 dias depois, nos retornos anormais acumulados, os autores evidenciaram: a) maiores retornos no período anterior à emissão de ADR's, indicando níveis superiores de custo de capital; b) retornos extras anormais positivos e significativos nos dias próximos ao evento, refletindo um aumento nos preços em função da redução do custo de capital; e c) retornos menores após a emissão de ADR's, indicando a redução do custo de capital.

Garcia, Sato e Caselani (2004) verificaram os efeitos do registro do programa de ADR's através de um estudo de evento com 18 empresas brasileiras que emitiram ADR's de Nível 2 ou 3. Para examinar esses efeitos, os autores utilizaram os modelos de retorno ajustados ao mercado e de retorno ajustados ao mercado e ao risco. Para cada um dos modelos realizaram-se testes com o objetivo de identificar se a emissão de ADR's de empresas brasileiras não exerce impacto na valoração das mesmas, refletido no preço das ações no mercado acionário brasileiro. Garcia, Sato e Caselani (2004) rejeitaram essa hipótese e concluíram que houve retornos anormais para o preço das ações das empresas da amostra do estudo, com o evento da concessão de registro de ADR's exercendo impacto na valoração das mesmas.

\section{CONCLUSÕES}

Nota-se, a partir das evidências empíricas comparativas dos índices da Bovespa em relação aos aspectos retorno e valor das empresas, liquidez, custo de captação e risco, que não houve unanimidade nas conclusões. As pesquisas, conforme evidenciadas no trabalho, apresentam resultados distintos nos diferentes aspectos analisados. A falta de conclusão na performance do IGC, ao analisá-lo em relação aos outros índices da Bovespa, entre outros motivos, pode ser devido:

a) como colocam Comerlato, Terra e Braga (2002, p.6), Aguiar, Corrar e Batistella (2004, p. 346) e Batistella et al. (2004, p.13), ao prazo de vida relativamente curto do IGC, o que tornam as conclusões incipientes - principalmente nos estudos mais antigos que usaram uma amostra pequena das observações desse índice;

b) ao reduzido número de empresas migradas para o Novo Mercado e os níveis diferenciados de governança, como acrescentam Coutinho, Oliveira e Da Motta (2003, p.12);

c) ao fato de algumas empresas pertencerem simultaneamente ao IGC e a outros índices - a maioria dos estudos apresentados, exceto o de Vieira e Mendes (2004), não con- sideraram esse aspecto;

d) ao fato de algumas empresas já possuírem boas práticas de governança corporativa bem antes da sua migração para os níveis diferenciados da Bovespa - aspecto esse que pode ser restrição nos estudos que analisaram a performance a partir da migração (estudo de eventos), como salientam Aguiar, Corrar e Batistella (2004, p.346);

e) em 29/09/2005, 38,03\% da carteira do IGC era composta de ações de três grandes bancos brasileiros, podendo, dessa forma, o IGC apresentar certa lacuna em representar empresas com práticas de governança superiores e/ou empresas do setor bancário, que historicamente têm apresentado melhor performance (ROGERS, 2006, p.117); e

f) os estudos consideram a dinâmica de curto prazo dos índices, e relegam que a performance do IGC possui equilíbrio a longo prazo, podendo, naturalmente, no curto prazo haver desequilíbrio, como coloca Rogers (2006, p.73).

Ao contrário dos estudos que relacionam a performance dos índices da Bovespa com as práticas de governança corporativa, os estudos com ADR's apresentaram certa convergência nas conclusões, mostrando, no geral, que as empresas que optaram pelo lançamento de ADR's apresentaram melhor performance após a emissão do recibo. A vantagem dos estudos de ADR's em relação aos índices da Bovespa é que eles podem ser desenvolvidos num período maior, já que os programas de ADR's iniciaram no Brasil em 1992 com a adesão da Aracruz Celulose e Votorantim (SILVEIRA, BARROS e FAMÁ, 2003, p.1).

Entretanto, as emissões de ADR's são feitas por empresas brasileiras de capital aberto de grande porte, o que pode viesar os resultados. Ademais, como salientam Silveira, Barros e Famá (2003, p.14), a performance evidenciada após o lançamento das ADR's pode sofrer influência não apenas de prováveis aperfeiçoamentos das práticas de governança corporativa das empresas emitentes, mas também devido ao acesso a um mercado mais líquido e eficiente e dos efeitos positivos da diversificação internacional e da conseqüente redução do risco sistêmico da ação.

Apesar das controvérsias e limitações nas diferentes metodologias ao analisar a performance comparativa do IGC, e da emissão de ADR's não representar efetivamente prováveis aperfeiçoamentos das práticas de governança corporativa das empresas, as evidências empíricas revisadas, no geral, mostram indícios que esses mecanismos externos de controle de governança corporativa pelo mercado de capitais no Brasil podem tornar essencial para aumentar o valor das empresas e alavancar o mercado de capitais nacional.

Como recomendações para futuros estudos ou investigações que possam trazer conclusões nessa área de estudo indica-se a formação de carteiras de empresas adotantes de boas práticas de governança corporativa em comparação com outras carteiras formadas por empresas não praticantes da "boa governança corporativa". Observa-se que essas carteiras devem ser formadas levando em conta várias 
estratégias de diversificação e ponderação da participação das ações das empresas, de forma que existam dois índices próprios: um de empresas com melhores práticas de governança corporativa e outro de empresas com práticas de governança corporativa inferiores. A análise comparativa desses dois índices nos diferentes critérios de performance: retorno e valor das ações, liquidez, custo de captação e risco, poderá trazer evidências mais contundentes à medida que elimina algumas limitações inerentes aos estudos apresentados nesse artigo.

\section{REFERÊNCIAS}

AGUIAR, A. B.; CORRAR, L. J.; BATISTELLA, F. D. Adoção de práticas de governança corporativa e o comportamento das ações na Bovespa: evidências empíricas. Revista de Administração da USP (RAUSP), São Paulo, v.39, n.4, p.338-347, out/ nov/dez. 2004.

ALENCAR, R.C.; LOPES, A. B. Custo de capital próprio e nível de disclosure nas empresas brasileiras. In: $5^{\circ}$ Congresso de Controladoria e Contabilidade, 2005, São Paulo. Anais ... São Paulo: FEA/USP, 2005 (CD-ROM).

ANDRADE, A.;ROSSETTTI, J. P. Governança Corporativa. São Paulo: Atlas, 2004.

BATISTELLA, F. D.; CORRAR, L. J.; BERGMANN, D. R.; AGUIAR, A. B. Retornos de ações e governança corporativa: um estudo de eventos. In: $4^{\circ}$ CONGRESSO DE CONTROLADORIA E CONTABILIDADE, 2004, São Paulo. Anais ... São Paulo: FEA/USP, 2004 (CD-ROM).

BERLE, A.; MEANS, G. The modern corporation and private property. New York: Macmillan, 1932.

BOLSA DE VALORES DE SÃO PAUlO (BOVESPA). Níveis diferenciados de governança corporativa. São Paulo: Bovespa, 2002. Disponível em: <http://www.novomercadobovespa.com. br/nm_publicacoes.shtml> Acesso em Junho de 2003.

BRUNI, A. L.; FAMÁ, R. Globalização financeira, eficiência informacional e custo de capital: uma análise das emissões de ADR's brasileiros no período 1992-2001. In: XXXVIII ASSEMBLÉIA DO CONSELHO LATINO-AMERICANO DAS ESCOLAS DE ADMINISTRAÇÃO (CLADEA), 2003, Lima. Anais ... Lima: CLADEA, 2003 (CD-ROM).

CARVAlHO, A. G. Governança Corporativa no Brasil em Perspectiva. Revista de Administração da USP, São Paulo, v. 37 , n.3, p.19-32, julho/setembro 2002.

Efeitos da Migração para os Níveis de Governança da Bovespa. São Paulo: Bovespa Abril/2003. Disponível em: <http://www.novomercadobovespa.com.br>. Acesso em Maio de 2003.

CASELANI, C.N.; EID JR, W. A influência dos determinantes microeconômicos e macroeconômicos sobre a volatilidade da ações negociadas no Brasil. V ENCONTRO BRASILEIRO DE FINANÇAS, Anais ..., Sociedade Brasileira de Finanças, 2005 (CD-ROM).

COMERLATO, G. M. B.; TERRA, P. R. S.; BRAGA, L. O. A reação do mercado acionário brasileiro às novas regras de governança cor- porativa da BOVESPA - um estudo empírico sobre o Nível 1. In: XXXVII ASSEMBLÉIA DO CONSELHO LATINO-AMERICANO DAS ESCOLAS DE ADMINISTRAÇÃO (CLADEA), 2002, Porto Alegre. Anais ... Porto Alegre: UFRGS, 2002 (CD-ROM).

COSTA JR, N. C. A. et al. Impacto da dupla negociação: um estudo de eventos de ADRs brasileiros. In: LEAL, R. C.; COSTA JR.,N. C. A.; LEMGRUBER, E.F (Org). Finanças Corporativas. São Paulo: Atlas, 2000.

COUTINHO, R. B. G.; OLIVEIRA, M. A. C.; DA MOTTA, L. F. J. Governança corporativa no Brasil: uma análise comparativa entre as rentabilidades do índice de ações com governança corporativa diferenciada (IGC), do IBOVESPA e do IBX. In: XXXVIII ASSEMBLÉIA DO CONSELHO LATINO-AMERICANO DAS ESCOLAS DE ADMINISTRAÇÃO (CLADEA), 2003, Lima. Anais ... Lima: CLADEA, 2003 (CD-ROM).

GARCIA, F. G.; SATO, L. G.; CASELANI, C N. O impacto da política de transparência sobre o valor das empresas brasileiras. In: XXVIII ENCONTRO DA ASSOCIAÇÃO NACIONAL DE PÓS-GRADUAÇÃO EM ADMINISTRAÇÃO (ENANAP), 2004, Curitiba. Anais ... Rio de Janeiro: ANPAD, 2004 (CD-ROM).

JENSEN, M. C.; MECKLING, W. H. Theory of the firm: managerial behavior, agency costs and ownership structure. Jornal of Financial Economics, v.3, p.305-360, Jul. 1976.

KLEIN, B. Contracting costs and residual claims: the separation of ownership and control. Journal of Law E Economics, v.26, p.367-373, June, 1983.

LA PORTA, R.; LOPEZ-DE-SILANES, F.; SHLEIFER, A.; VISHNY, R. Law and finance. Journal of Political Economy, Chicago, v.106, n.6, p.1113-1155, Dec. 1998.

. Corporate ownership around the world. Journal of Finance, Malden, v.54, n.2, p.471-518, Apr. 1999.

LAMEIRA, V.J.; NESS JR, W.L.; DA MOTTA, L.F.J. Governança corporativa: existe evidências empíricas de impactos no $\beta$ e $\mathrm{D}-\beta$. V ENCONTRO BRASILEIRO DE FINANÇAS, Anais ..., Sociedade Brasileira de Finanças, 2005 (CD-ROM).

LAMEIRA, V.J.; NESS JR, W.L.; SOARES, T.D. Governança corporativa: impactos no valor das companhias abertas brasileiras. In: V Encontro Brasileiro de Finanças, Anais ..., Sociedade Brasileira de Finanças, 2005 (CD-ROM).

LIMA, I. S.; IKEDA, R. H.; SALOTTI, B. M.; BATISTELLA, F. D. O custo de captação e a governança corporativa. In: $17^{\circ}$ CONGRESSO BRASILEIRO DE CONTABILIDADE, 2004, São Paulo. Anais ..., 2004 (CD-ROM).

LIMA, J. B. N.; TERRA, P. R. S. Governança corporativa e a reação do mercado de capitais às informações financeiras. In: XXVIII ENCONTRO DA ASSOCIAÇÃO NACIONAL DE PÓS-GRADUAÇÃO EM ADMINISTRAÇÃO (ENANAP), 2004, Curitiba. Anais ... Rio de Janeiro: ANPAD, 2004 (CD-ROM).

RODRIGUES, E. L. Maior visibilidade ou integração do mercado de capitais brasileiro? Os efeitos da listagem de ações de empresas brasileiras no mercado norte americano através do mecanismo de recibos de depósitos de ações. Revista da CVM, Rio de Janeiro, n. 29, p.29-51, Ago 1999. 
ROGERS, P. Governança corporativa, mercado de capitais e crescimento econômico no Brasil. Uberlândia: Universidade Federal de Uberlândia - Faculdade de Gestão e Negócios (UFU/FAGEN), 2006. (Dissertação de Mestrado).

ROGERS, P.; RIBEIRO, K.C.S; SOUSA, A. F. Variáveis Influenciadoras da Governança Corporativa no Brasil: Análise Comparativa do IGC e do Ibovespa. In: X ENCONTRO BRASILEIRO DE FINANÇAS, 2005, São Paulo. Anais ... São Paulo: SBF, 2005 (CD-ROM).

SILVEIRA, H. P.; BARROS, L. A.C.; FAMÁ, R. Impacto da emissão de ADR's sobre retorno e volatilidade de empresas brasileiras: um estudo de evento. In: XXXVIII ASSEMBLÉIA DO CONSELHO LATINO-AMERICANO DAS ESCOLAS DE ADMINISTRAÇ̃̃O (CLADEA), 2003, Lima. Anais ... Lima: CLADEA, 2003 (CD-ROM).
SROUR, G. Práticas Diferenciadas de Governança Corporativa: um estudo sobre a conduta e a performance das firmas brasileiras. ENCONTRO BRASILEIRO DE FINANÇAS, Anais ..., Sociedade Brasileira de Finanças, 2002. Disponível em: <http://www. sbfin.org.br>. Acesso em Julho de 2003.

VIEIRA, E. R.; CORRÊA, V. P. Mercado de Capitais e Governança Corporativa no Brasil: reflexões sobre os movimentos recentes. Fórum Banco do Nordeste de Desenvolvimento, VII ENCONTRO REGIONAL DE ECONOMIA, Anais..., Fortaleza, Julho de 2002.

VIEIRA, S. P.; MENDES, A. G. S. Governança corporativa: uma análise de sua evolução e impactos no mercado de capitais brasileiro. Revista do BNDES, Rio de Janeiro, v.11, n.22, p.103-122, Dez. 2004. 